\title{
PROCESSO DE REABILITAÇÃO PROFISSIONAL SOB A PERSPECTIVA DO SEGURADO DA PREVIDÊNCIA SOCIAL
}

\author{
PROCESS OF PROFESSIONAL REHABILITATION UNDER THE PERSPECTIVE OF THE \\ SOCIAL SECURITY INSURED
}

Tatiane Rodrigues Araújo Lima ${ }^{\mathrm{I}}$

\section{RESUMO}

O artigo discute a problemática do segurado no processo de reabilitação profissional, que é um direto constitucional, garantido ao segurado que após acidente de trabalho ou doença ocupacional não encontra-se apto para retornar ao seu posto de trabalho. Assim, essa pesquisa tem o objetivo de descrever a condição socioeconômica do segurado da previdência social, considerando o processo de reabilitação profissional de um município do interior do Estado de Goiás. Para isso realizou uma pesquisa qualitativa, recorrendo entrevista com 02 que foram gravadas, transcritas e exploradas neste texto. Os resultados obtidos sugerem que o processo de reabilitação profissional, ainda precisa de mais investimentos com vistas na reinserção dos assegurados, pois é realizado sem o eficiente acompanhamento do INSS e das empresas. Observou-se que o INSS de um lado querendo reabilitar o segurado e a empresa de outro muitas vezes esquivando-se de suas responsabilidades, ao invés de realizar os investimentos necessários para acolhida desse segurado, que ainda encontra-se fragilizado e traumatizado após um acidente de trabalho ou doença ocupacional. Além disto, neste processo o segurado é submetido as várias perícias e tratamentos médicas, intervenções cirúrgicas e a participação no Processo de Reabilitação Profissional que é de caráter obrigatório.

Palavras-chave: Empresas. Política da Previdência Social. Segurado. Reabilitação Profissional.

\section{ABSTRACT}

The article discusses the problem of the insured in the process of professional rehabilitation, which is a constitutional direct, guaranteed to the insured that after an accident at work or occupational disease is not fit to return to his job. Thus, this research has the objective of describing the socioeconomic condition of the social security insured, considering the process of professional rehabilitation of a municipality in the interior of the State of Goiás. For this, he conducted a qualitative research, using an interview with 02 that were recorded, transcribed and explored in this text. The results suggest that the professional rehabilitation process still needs more investments with a view to the reintegration of the insured, since it is carried out without the efficient monitoring of the INSS and the companies. It was observed that the INSS on the one hand wanting to rehabilitate the insured and the company of another often avoiding their responsibilities, instead of making the necessary investments to receive this insured, who is still fragile and traumatized after an accident occupational disease. In addition, in this process the insured is subjected to various medical examinations and treatments, surgical interventions and participation in the Professional Rehabilitation Process which is mandatory.

Keywords: Companies. Social Security Policy. Insured. Professional Rehabilitation.

\footnotetext{
${ }^{\mathrm{I}}$ Prefeitura Municipal de Mineiros/Goiás Brasil. E-mail: tatianerarl@ gmail.com
} 


\section{INTRODUÇÃO}

O cenário atual do Instituto Nacional do Seguro Social (INSS) apresenta fragilidades, quanto ao atendimento do segurado do Programa de Reabilitação Profissional, tornando os processos demorados e sem uma resposta eficiente ao segurado. Tal aspecto, sustenta a relevância de pesquisa nesta temática, por possibilitar trazer a vivência do segurado sobre uma realidade que nem sempre é percebida no processo de reabilitação profissional.

A seguridade social é composta por um tripé de direitos que que abrange a área da saúde, da previdência social e da assistência social. Sua finalidade é promover o bem - estar que garante os mínimos necessários à sobrevivência do indivíduo, atenuando nas situações de desigualdades sociais. Quanto a este aspecto, no artigo 194 da Constituição Federal estabelece como: "conjunto integrado de ações de iniciativa dos Poderes Públicos e da sociedade, destinada a assegurar os direitos relativos à saúde, à previdência e a assistência social" (BRASIL, 1988).

O principal regime previdenciário que abrange o maior contingente de pessoas do país é o Regime Geral de Previdência Social (RGPS). Os benefícios emitidos pelo RGPS funcionam como um seguro social para o trabalhador e sua família, através do INSS que garante a reposição da renda do trabalhador contribuinte quando este perde a capacidade de trabalho, devido a doença, invalidez, idade avançada, morte e desemprego involuntário, ou mesmo em razão de maternidade e reclusão.
Dentre os serviços e benefícios concedidos pelo INSS, há o processo de reabilitação profissional ele ocorre quando o segurado sofre um acidente de trabalho ou por doença ocupacional. O trabalhador, por estar inapto ao trabalho fica afastado e inicia o processo de reabilitação com uma equipe multidisciplinar (médicos, assistentes sociais, psicólogos, sociólogos, fisioterapeutas entre outros), com o objetivo de reabilitar esse segurado até sua reinserção ao mercado de trabalho.

O processo de reabilitação profissional do segurado deve ser desenvolvido por meio das funções básicas, como: avaliação do potencial laborativo, orientação e acompanhamento da programação profissional, articulação com a comunidade e acompanhamento e pesquisa da fixação no mercado de trabalho. Entretanto, o modelo atual do Programa de Reabilitação Profissional tem sido alvo de críticas de vários estudos, seja pela falta de atendimento das necessidades de saúde dos trabalhadores, seja também pelo modelo de avaliação de incapacidade adotado, caracterizando-a como reducionista (SARDÁ; KUPECK 2009; CHEREM; et al, 2009).

Através de um percurso histórico, observamse que na década de 90 vigorava o estado mínimo e os Serviços de Reabilitação Profissional passaram por mudanças significativas com completa desativação dos Centros de Reabilitação Profissional (CRP) do INSS. Em torno de uma década depois, no ano 2012, existiam no INSS cerca de 1360 Agências da Previdência Social; dessas, apenas 417 disponibilizavam serviços de Reabilitação Profissional, na modalidade de 
equipes fixas e outras 219 não tinham equipes próprias e contavam com equipes volantes de Reabilitação Profissional que se deslocavam para atender seus segurados (BRASIL, 2014).

Ainda em 2012, o INSS considerou elegível para o programa de Reabilitação Profissional, totalizando 31.401 segurados, dos quais foram reabilitados apenas 17.387 pessoas. Na prática, um número bem aquém do esperado, tanto do ponto de vista institucional, quanto das necessidades postas e das filas que se formam à espera desse serviço. Atualmente cerca de 34.970 trabalhadores aguardam o primeiro atendimento nas Gerências Executivas do INSS (BRASIL, 2014).

$\mathrm{Na}$ atual definição da seguridade social, o Estado passa ter a responsabilidade na criação de uma rede de proteção capaz de atender as necessidades de todos os cidadãos na área social. Vejamos seu conceito no Art 194 da CF: "conjunto integrado de ações de iniciativa dos Poderes Públicos e da sociedade, destinadas a assegurar os direitos relativos à saúde, à previdência e a assistência social". Diante do exposto pode-se dizer que a solidariedade é o fundamento da seguridade social, diante do dever constitucional imposto aos poderes públicos e à sociedade (SANTOS, 2011).

Segundo Ibrahim (2012), a seguridade social pode ser conceituada como uma rede protetiva, em que o Estado e a contribuição de todos (incluindo dos beneficiários) possibilite a manutenção para um padrão mínimo de vida digna, no sustento trabalhadores em geral e seus dependentes e de pessoas carentes. A seguridade social possibilita a efetivação do bem estar social garantindo os mínimos necessários à sobrevivência do indivíduo, atenuando as desigualdades sociais, ou seja, um meio para atingir a justiça, que é o objetivo da ordem social (BRASIL, 1988).

A seguridade social terá duas vias de acesso as demandas sociais, sendo a via previdenciária (seguro social) e a via assistencial (integrada por dois distintos sistemas: saúde e assistência social) (BARELA, 2010), compreendendo três áreas distintas que ao se integrar formam um sistema protetivo completo. Para Santos (2011), a seguridade social é formada por um tripé: previdência social, direito a saúde e a assistência social, que são institutos disciplinados/ regidos pela Constituição Federal. É válido observar alguns requisitos específicos quanto a prestação da seguridade social.

Quando o indivíduo fica limitado na promoção do seu sustento ou de sua família por razões de doença, desemprego, maternidade, invalidez, reclusão ou outras razões; ele recorre à seguridade social. Se for segurado da previdência social, a proteção social será efetivada através do pagamento do benefício compatível à necessidade e ainda terá o direto a serviços da assistência à saúde. Já nos casos, em que o indivíduo não for segurado de nenhum regime previdenciário, o mesmo terá direito aos benefícios e serviços de assistência social, desde que preencha os requisitos legais. As prestações de benefícios e serviços, de natureza previdenciária incluem segurado e dependentes.

- Quanto ao Segurado: aposentadoria por idade, aposentadoria por tempo de contribuição, aposentadoria especial, 
aposentadoria por invalidez, auxílio doença, auxílio - acidente, salário família e salário - maternidade.

- Quanto aos dependentes: pensão por morte e auxílio - reclusão.

- Quanto ao segurado e dependente: serviço social e reabilitação profissional.

A saúde insere-se no sistema de seguridade social justamente por amparar a população com as possíveis doenças, ou em face das doenças já existentes na sociedade, conferindo proteção a quem quer que necessite, sem exigir qualquer contraprestação (BARELA, 2010, p 20). O serviço de assistência à saúde é dever do Estado e por ele deve ser garantido, mas quando ocorre falta ou deficiência do serviço acarretando dano ao usuário, o Estado pode sofrer sanções e a obrigação de indenizar o usuário (SANTOS, 2011).

A proteção à saúde advêm de ações e serviços e não através de pagamento de benefícios. Por isso, não se deve confundir a proteção à saúde com a proteção dada pela previdência social nas contingências de doença ou invalidez. Afinal o auxílio - doença e aposentadoria por invalidez são benefícios previdenciários, previsto no Regime Geral de Previdência Social - RGPS que é administrada pelo Instituto Nacional do Seguro Social - INSS.

Na condição de autarquia, o INSS é dotado de personalidade jurídica de direito público, vinculada ao Ministério da Previdência Social MPS, e é responsável pelo recolhimento das contribuições e custeio das despesas com o pagamento dos benefícios do Sistema Único de Benefício (SUB). A cobertura previdenciária destina-se aos seus beneficiários que são classificados em: segurados e dependentes.

Os segurados são sempre pessoas físicas vinculadas ao RGPS, e que, em contrapartida têm o direto na prestação dos benéficos de cunho previdenciário. Os segurados da previdência são classificados em: empregado, empregado doméstico, trabalhador avulso, contribuinte individual, segurado especial e facultativo. A seguir vamos explanar dois benefícios que estão interligados com o processo de reabilitação profissional, que são: auxílio- doença e o auxílio acidente. O benéfico de auxílio - doença é concedido ao segurado que encontra-se impossibilitado de exercer suas atividades por mais de 15 dias, em decorrência de doença ou acidente.

No caso dos trabalhadores com carteira assinada, os primeiros 15 dias são pagos pela empresa (empregador), e a partir do $16^{\circ}$ a previdência social é responsável pelo pagamento. Lembramos que o benefício somente será pago pela previdência social se comprovada à incapacidade laborativa desse segurado, mediante perícia médica por médico perito do INSS. Para CRUZ o auxílio doença:

[...] é o benefício devido ao segurado da previdência social que ficar incapacitado para o seu trabalho ou para sua atividade habitual, por mais de quinze dias consecutivos. A doença, por si só, não garante o benefício, ela deve deixar o segurando incapacitado para o trabalho. Salientese que o auxílio-doença é disponível a todos os segurados, desde que estes cumpram, em regra, a carência de 12 contribuições mensais (2014).

Existe também a questão da carência, período 
de 12 meses de contribuição para que o segurado possa requerer o benefício. No caso de acidente de qualquer natureza (acidente de trabalho ou fora do trabalho), ou quando for acometido de alguma doença grave ${ }^{2}$ o segurado fica isento dessa regra.

E todos os acidentes de trabalho, mesmo aqueles que não haja afastamento devem ser notificados à previdência social até o $1^{\circ}$ dia útil seguinte ao da ocorrência. Nos casos de morte, essa comunicação deve ser imediata. A empresa que não cumprir estará sujeita à multa. A comunicação de acidente de trabalho ou doença ocupacional será feita à previdência Social pela emissão de formulário próprio, a CATComunicação de Acidente de Trabalho.

\begin{abstract}
A CAT deverá ser emitida pela empresa ou pelo próprio trabalhador, por seus dependentes, pela entidade sindical, pelo médico ou por autoridade (magistrados, membros do Ministério Público e dos serviços jurídicos da União, dos estados [...]. O formulário preenchido tem que ser entregue em uma Agência da Previdência Social pelo emitente (GUIZZO, pg. 47).
\end{abstract}

Existem também doenças que são oriundas da atividade laborativa, e se for estabelecido pelo INSS o nexo técnico, pode equiparar-se a acidente de trabalho, e por isso também ficam isentos de carência. O auxilio - doença deixa de ser pago quando o segurado recupera sua capacidade laborativa e retorna ao trabalho ou quando $\mathrm{o}$ benefício se transforma em aposentadoria por invalidez.

Durante o período que o trabalhador estiver afastado e recebendo o beneficio de auxilio doença, será necessário a realização de exames médicos periódicos e perícias. O auxílio-acidente é concedido ao segurado que sofre um acidente, e em decorrência do mesmo fica com sequelas que reduzem permanentemente sua capacidade para o trabalho.

Tavares (2000) caracteriza como auxílioacidente a indenização paga ao segurado que após acidente de qualquer natureza, resultam sequelas que implicam na redução da capacidade para o trabalho e impossibilidade de desempenhar as atividades que exercia antes da época do acidente. O auxílio- acidente geralmente é destinado aos segurados que se acidentaram no exercício da atividade a serviço da empresa, provocando lesão corporal ou perturbação funcional, causando à perda da redução permanente ou temporária da capacidade para o trabalho.

A concessão do auxílio-acidente não exige tempo mínimo de contribuição, e é um benefício que tem caráter indenizatório, podendo ser acumulado com outros benefícios, com exceção da aposentadoria, pois este deixa de ser pago quando o trabalhador se aposenta. Os acidentes de trabalho são classificados em três tipos: acidente típico, doença profissional e acidente de trajeto.

$\mathrm{O}$ resultado do afastamento por auxilio doença ou acidente de trabalho pode ser a incapacidade para o trabalho que possui implicações sociais, econômicas e para a saúde pública. Neste contexto, diversos são os aspectos a serem considerados. Entre eles destaca-se o fato de que os afastamentos têm um efeito negativo sobre as empresas e a economia em geral, resultando na redução da força de trabalho e no aumento do custo da produção, médico, previdenciário e social. 
Os danos à saúde do trabalhador vêm acompanhando o processo de crescimento socioeconômico e industrial, assim como a consequiente diversificação dos processos produtivos, os quais expõem os trabalhadores a riscos ambientais. É importante salientar que existem também aqueles casos em que o segurado após período afastado (por motivo de doença ou acidente), ainda encontra-se inapto ao trabalho por incapacidade parcial ou total.

Nesta pesquisa foi colocado em tela a saúde do trabalhador. Assim, o objetivo foi descrever a condição socioeconômica do segurado da previdência social, considerando o processo de reabilitação profissional de um município do interior do Estado de Goiás.

\section{MATERIAL E MÉTODO}

Num município do interior da região Sudoeste do Estado de Goiás, há uma agência da Previdência Social com capacidade para realizar, em média 1.400 atendimentos mensais e 924 perícias médicas. Além dos habitantes do município, a unidade da Previdência Social atende também a população das cidades circunvizinhas localizadas nesta região.

Este contexto despertou o interesse pela temática Reabilitação Profissional, e consequentemente, definir o objeto de estudo: condição socioeconômica do segurado da previdência social no processo de reabilitação profissional do município do interior do Estado do Goiás.

$\mathrm{Na}$ elaboração desta pesquia foi realizada a entrevista para construção das informações. A escolha dos participantes se deu de maneira aleatória, sendo 2 segurados da previdência social, que passaram pelo processo de reabilitação professional, numa cidade do interior do Estado de Goiás.

\section{RESULTADOS E DISCUSSÃO}

$\mathrm{O}$ acesso aos serviços previdenciários no Brasil, desde seus primórdios configurou-se como um direito trabalhista das classes assalariadas. Considerado como um seguro e gerenciado pelo Estado mediante a inserção formal no mercado de trabalho. Inicialmente esse seguro ficou restrito a alguns setores específicos, coberto pelas Caixas de Aposentadorias e Pensões (CAPs) e pelos Institutos de Aposentadorias e Pensões (IAPs), que posteriormente unificou surgindo o Instituto Nacional de Previdência Social (INPS), e depois Instituto Nacional de Seguro Social (INSS).

Inicialmente o projeto dos centros de reabilitação profissional (CRP), no INSS era de uma concepção de excelência, na qual se disponibilizavam de recursos terapêuticos necessários, equipamentos de fisioterapia e terapia ocupacional de alto custo, articulado a uma equipe de multiprofissionais formados por: médicos, assistentes sociais, psicólogos, terapeutas ocupacionais, enfermeiros, fisioterapeutas, pedagogos, sociólogos e fonoaudiólogos.

\subsection{Reabilitação Profissional e dos participantes da pesquisa}

As Gerências Executivas (GEX) se estruturam para a prestação do serviço de Reabilitação Profissional, sendo responsável pelo Serviço/Seção de Saúde do Trabalhador (SST) a supervisão e o acompanhamento das ações do 
referido serviço. É o responsável do SST que solicita ao Gerente-Executivo a designação de um Responsável Técnico da Reabilitação Profissional (servidor de nível superior de área afim da RP), o qual junto com a Equipe de Reabilitação Profissional nas Agências da Previdência Social (ERPAPS) — constituída por Peritos Médicos do INSS e Analistas do Seguro Social com formação nas áreas de Serviço Social, Psicologia, Sociologia, Fisioterapia, Terapia Ocupacional e outras áreas afins à RP e os servidores administrativos (denominados Técnicos do Seguro Social), que o quadro de profissionais que atuam no serviço de Reabilitação Profissional (RP) (INSTITUTO NACIONAL DO SEGURO SOCIAL, 2011).

Assim, as atribuições da equipe de Reabilitação Profissional são: realizar a avaliação do segurado, verificando seu potencial laborativo; planejar; conduzir e finalizar o Programa de Reabilitação Profissional (INSTITUTO NACIONAL DO SEGURO SOCIAL, 2011). Em 2001 foi implantado o Projeto Reabilita, vigente nos dias atuais, fundamentado no regulamento da Previdência Social, tem por finalidade nomear orientadores profissionais, e não mais as equipes de profissionais para realizar o processo de recolocação institucional do segurado da RP. O fato é que muitos desses orientadores profissionais não têm familiaridade com o mundo real do trabalho, seus desafios, exigências e suas complexidades. Assim, a atuação do orientador profissional restringe-se, apenas, a condução do processo precário de reinserção do segurado minimizando a interferência do Estado.
Não há sequer um programa de reabilitação profissional traçado por esses orientadores profissionais para cada caso. Com freqüência, seus procedimentos restringemse a entrevistar o reabilitado e a encaminhálo à perícia do órgão, solicitando à empresa de vínculo informações sobre o cargo a lhe ser oferecido. Sem uma avaliação criteriosa da atividade laboral oferecida pela empresa, promove-se um estágio, que, cumprido de alguma forma, resulta na homologação da reabilitação do segurado, independente das condições reais e efetiva reinserção no ambiente de trabalho (MAENO, VILELA, 2010, p. 91).

O fluxo de atendimento da Reabilitação Profissional inicia-se na própria agência da Previdência Social, onde o segurado que já está em acompanhamento fará a Avaliação do Potencial Laborativo pela Perícia Médica. Em seguida, o Responsável pela Orientação Profissional realiza a avaliação dos aspectos socioprofissional do segurado e, posteriormente, ambos se reúnem para a avaliação conjunta para definir se o segurado é ou não elegível para o Programa de Reabilitação Profissional, mediante parecer técnico conclusivo.

Caso o segurado seja elegível a RP o segurado deverá obrigatoriamente participar da reunião do Grupo Informativo (GI) para ser orientado acerca do processo de RP.

O regulamento da lei previdenciária cita alguns procedimentos, incluindo a avaliação do potencial labiorativo, a orientação e o acompanhamento da programação profissional, a articulação com a comunidade com vistas ao reingresso no mercado de trabalho e acompanhamento e pesquisa de fixação, preferencialmente por uma equipe multiprofissional (MAENO, VILELA, 2010, p. 89).

Após a definição do vínculo empregatício o Responsável pela Orientação Profissional contatará a empresa/instituição de vínculo, com a 
finalidade do retorno do segurado para a mesma função que desempenhava e se não for possível busca-se uma nova função/atividade compatível considerando as limitações / restrições do mesmo. A duração desse processo vai de acordo com o tempo necessário para a reinserção do segurado a empresa. Em alguns casos é necessário o segurado realizar alguns treinamentos em funções diferentes até que seja definida qual a função mais compatível para o segurado. $\mathrm{Na}$ legislação atual o direito a reabilitação profissional foi estendido também aos dependentes.

Nos casos em que o segurado não possui vínculo empregatício e aqueles em que não há função compatível na empresa ou há impossibilidade de readaptação profissional, é realizado o encaminhamento destes para capacitação mediante cursos/treinamentos na comunidade. Compete ainda o INSS através do PRP fornecer ao segurado materiais para reabilitação como: órteses, próteses, custeio de taxas de inscrição como das mensalidades dos cursos oferecidos, auxílio transporte e alimentação.

Quanto aos entrevistados da presente pesquisa, o Particpante A, solteiro, 39 anos ficou 01 ano em processo de reabilitação. Já o participante B, casado, 34 anos, ficou 06 meses em reabilitação profissional. No depoimentodo Participante B realatou que: “[...] passei por reabilitação profissional, e a orientadora falou que eu tinha que voltar ao serviço, que eu tinha o mesmo direito que os outros funcionários tinham".

Estes participantes deveriam ao ter concluído o PRP e conforme Art 92 da Lei $n^{\circ}$. 8.213/1991, a Previdência Social emitirá certificado individual, indicando as atividades que poderão ser exercidas pelo beneficiário, nada impedindo que este exerça outra atividade para a qual se capacitar.

O segurado reabilitado quando é reinserido ao trabalho, usufrui de estabilidade por tempo determinado, e a dispensa do trabalhador reabilitado só ocorrerá após passado o período de estabilidade, e desde que seja substituído por outro trabalhador de condição semelhante. $\mathrm{O}$ segurado também preenche os requisitos de cota para beneficiários reabilitados ou pessoas portadoras de deficiência conforme o Art 140 da Lei $n^{\circ}$. $8.213 / 1991$, que estabelece as empresas com até 200 empregados cumpra a cota de 2\%, 201 a 500 empregados a cota de 3\%, 501 a 1.000 empregados a cota de $4 \%$ e acima de 1.001 empregados a cota de $5 \%$.

As gerências executivas estão estruturadas em unidades nas capitais e grandes cidades do interior, o que pode trazer transtornos ao segurado quanto seu deslocamento. E como o PRP é de caráter obrigatório, sendo imprescindível sua frequência, sujeito a suspensão do benefício caso não ocorra. Quanto a isto, o Participante B salientou que:

[...] teve uma vez que eu fui e eles não queriam pagar minha passagem. Foi tenso mesmo. Eu já estava lá e eu não tinha como voltar para casa, e o direito é pagar a passagem do reabilitado, e eles não queriam me pagar. Eu fiquei lá por volta de umas 02 horas esperando, colocando pressão em mim, e foi onde eu falei: se vocês não pagar não tem como eu voltar, eu vou ter que ficar aqui ou chamar o ministério público, ou fazer qualquer coisa. Ai depois de 02 horas eles pagaram. (Participante B). 
Ainda no período de afastamento, antes do segurado ser inserido no PRP, ele necessita de tratamento médico, intervenções cirúrgicas (quando indicado por médico) ou reabilitação física (terapia ocupacional, fisioterapia). E nesse contexto o segurado deveria ter a cobertura pela Previdência social, pelo SUS e também pela empresa, ou seja, no momento que ele mais precisa de suporte, ele pouco encontra ou nem encontra, nos relatos dos participantes é possível observar essas questões:

Da empresa, para falar a verdade eu não recebi suporte. Eu cheguei até passar necessidade em casa. Quando eu adoeci, meu filho não tinha nem 01 ano. Teve dias que eu não tinha nada para comer em casa. [...] Então eu sou revoltada com a empresa por isso. Porque assim, eu era trabalhadora, não tinha falta, não tinha problema com a empresa, e assim eu não recebi nenhum apoio. Eu não tinha condições de nem tomar banho sozinha, nem de higienizar meu corpo[...]. Então as pessoas próximas de mim é que me apoiaram. A pessoa que trabalha com carteira assinada, que é um cidadão que trabalha, não falta e que é honesta no seu trabalho e quando adoece não tem apoio da empresa. Isso é humilhante. Do município eu recebi, da prefeitura ganhei passagem, e me deram apoio para fazer um exame de ressonância, que a empresa tinha que ter pago, mas eles não pagaram, foi a prefeitura que arcou (Participante A).

Realizei 5 cirurgias, sendo 4 pelo SUS e apenas 01 a empresa arcou. Do município não tive suporte (Participante $\mathrm{B}$ ).

Nas entrevistas é possível constatar essa realidade. Quando se trata de acidente de trabalho ou doença ocupacional a empresa deveria prestar assistência ao trabalhador, garantindo-lhe acesso ao tratamento. Mas, os relatos demonstram que as empresas se eximem da responsabilidade e “jogam" a responsabilidade para o município ou até para o próprio trabalhador. $\mathrm{O}$ município embora tenha o seu sistema de saúde, nem sempre dispõe estrutura adequada para o atendimento. $\mathrm{O}$ município dispõe, apenas, de um hospital conveniado pelo SUS e 04 hospitais particulares. O conveniado pelo SUS presta atendimento à atenção básica e mantém convênios com outras cidades. Assim, o trabalhador precisa esperar na fila para ser atendido. $\mathrm{O}$ trabalhador por sua vez, não tem outra opção se não custear seu tratamento médico.

A assistência à saúde para o segurado, deveria ocorrer segundo a dinâmica e diretriz do SUS, como já mencionado no capítulo I desse trabalho. Porém, o que observou foi a demora no acesso aos procedimentos que, na maioria das vezes, são de alta complexidade. A dificuldade de acesso implica no atraso do tratamento médico cirúrgico e da reabilitação física ou psicológica, resultando maior tempo de afastamento do trabalho (SAMPAIO, 2003), conseqüentemente, tardando a introdução no programa de reabilitação profissional, que deveria ser feito o mais rápido possível.

Nesse contexo ocorre um "jogo de empurra" entre a empresa e a instituição do INSS. De um lado o trabalhador ainda adoecido tendo que se submeter à peregrinação do PRP, do outro o INSS tentando reabilitar o trabalhador na empresa. As empresas muitas vezes, a fim de evitar multas e de cumprir as exigências legais reinserem o acidentado, mas não proporcionam a esse trabalhador plena recolocação, respeitando os atuais limites que atendam também ao desejo do trabalhador consideração suas habilidades e aptidões. 
Quanto ao processo de reinserção ao trabalho na empresa, foi possível observer como ocorre a partir da fala dos participantes.

Após a alta da reabilitação, eu estava muito cansada, pois foi desgastante esse processo e quando voltei para empresa ficaram me jogando de um lado para o outro até me adaptar em alguma função. O dever deles era esse. Então foi difícil, a empresa não foi honesta comigo. Quando você começa a fazer uma reabilitação profissional na empresa, você ainda fica a mercê dos cuidados do INSS, e querendo ou não, mesmo o INSS com as falhas que ele tem, isso causa certo constrangimento para a empresa, e eles (empresa) ficam te poupando, mas quando passa o período da reabilitação, que você sai fora dos cuidados do INSS a empresa começa te punir pelo que você não fez, eles colocam pressão, te colocam em atividades que você não pode fazer, serviço pesado e você é tratado com descaso. A partir do momento que você não pode exercer sua função, até mesmo por acidente de trabalho você é tratado com descaso, e as pessoas que fazem reabilitação profissional por muito tempo, como eu fiz se sente dessa forma, por que eu conversei com várias pessoas, a gente se sente um lixo, a realidade é essa (Participante A).

Foi bom, me adaptei a função. Por enquanto está bom. E se eles me colocaram ali creio que era porque precisava (Participante B).

\section{O PRP deveria continuar no} acompanhamento dos casos, mas na prática, a sua responsabilidade ocorre mediante a alta do trabalhador considerado reabilitado (SAMPAIO, 1999, p. 810). E isso ocorre sem considerer o trabalhador na sua integralidade, sem considerando mais os aspectos econômicos do que os sociais e emocionais do segurado, pois sabe-se que o rompimento ou perda do vínculo empregatício, causa na vida do trabalhador não, apenas, perdas econômicas, mas afeta também o bem-estar físico, familiar, psicológico, comportamental e social.

Segundo Matsuo (1998), o trabalhador acidentado ou com doença ocupacional sofre dupla exclusão no âmbito/mundo do trabalho. A primeira é econômica, pois o trabalhador perde sua condição de trabalhador produtivo, e sua remuneração passa a limitar-se ao benefício da previdência social. E a segunda, é social, pois o trabalhador deixa de ter autonomia, torna-se inválido, dependente e vítima de preconceitos.

Para este trabalhador afastado de seu trabalho, as condições de inserção são mais difíceis, seja pela perda de determinadas funções, habilidades e temores quanto ao futuro profissional. Um acidente de trabalho pode implicar na ruptura da construção da identidade profissional, na medida em que o papel assumido pelo indivíduo, assim como em todas as expectativas sociais e os projetos de vida relacionados à profissão são drasticamente modificados. Além disso, o indivíduo acidentado passa a pertencer a uma categoria relacionada a atributos de desprestígio e desqualificação social/profissional como, perda de papel profissional; estar doente ou ser inválido e não ter perspectivas de futuro; ser inútil/improdutivo. Ou seja, um acidente de trabalho interfere na objetivação-subjetivação da realidade e o indivíduo acidentado passa a ter novas relações com os outros, com o mundo e com seus próprios projetos (ROSIN-PINOLA; SILVA; GARBULHO, 2004, p. 55).

A Reabilitação Profissional nem sempre é sinônimo de garantia para o trabalhador, ou seja, não é a certeza que permanecerá na empresa, pois em alguns casos, passado o período de estabilidade muitos desses trabalhardes são desligados. Em outros casos o trabalhador diante do sofrimento para adaptação da nova função opta 
em desligar-se da empresa.

A recolocação desse trabalhador no mercado de trabalho é algo desafiante, pois o empregador busca produtividade e a maioria das empresas não compartilham da visão de inclusão, até porque isso resultaria adaptações e conseqüentemente em investimentos por parte do empregador. Algumas consequências da reabilitação foram elencadas pelos participantes da presente pesquisa.

Após a reabilitação e o acidente de trabalho, minha vida teve várias mudanças. Eu tive que aprender a trabalhar de outras formas. $\mathrm{Eu}$ tive que aprender a adaptar com dores, dores às vezes de passar 3 dias internada. Eu não consigo mais levantar minhas mãos acima dos ombros, isso me deixou um pouco insegura. Eu não consigo cuidar mais da minha casa como fazia antigamente. Eu deixei de ter meu filho no colo. Meu filho cresceu antes da hora, porque eu não posso mais pegar peso. Então, foi um processo bem doloroso para mim, e até hoje eu sofro conseqüências. Por isso, quando arrumo um novo trabalho eu tenho que dizer o que ocorre comigo, então às vezes é desafiante pra mim, pois se é um serviço que eu tenha que pegar peso, logo sou dispensada do trabalho. Eu Ainda sou jovem, e poderia trabalhar muito mais e ter uma vida mais digna. E em virtude desse ocorrido eu deixei de fazer muitas coisas que eu fazia antes. Eu realmente sou muito triste por isso (Participante A).

Ao invés de ficar em casa parado, voltar ao trabalho foi bom. Pois, não é bom ficar parado. Tenho ainda dificuldade motora, mas nada que não dê um jeitinho (Participante B).

Para Martins e Assunção (2002), o rompimento involuntário com o mundo do trabalho é vivenciado pelo trabalhador com o sofrimento de ser marginalizado, estigmatizado, desvalorizado e a perca do reconhecimento do seu passado profissional. São pessoas doentes, com alguma limitação para o trabalho, estigmatizados de uma identidade de "trabalhador doente" (BRANT; MINAYO-GOMEZ, 2004, p. 13). O estigma bloqueia a aceitação social plena, reduzindo o trabalhador a inabilitado, não correspondendo as exigências de uma sociedade capitalista, em que a força de trabalho é exigida (GOFFMAN, 1982; BARROS; SALES; NOGUEIRA, 2002). Isso acontece até mesmo para atividades simples que fazem parte do cotidiano do trabalhador, que na sua essência é um ser humano.

O afastamento do trabalho pelo segurado da Previdência social é um direito legal, mas que é reinterpretado pela lógica da redução de custos da previdência. Nesse processo o segurado sofre uma série de constrangimentos, desde a peregrinação para comprovação da sua doença, e quando indicado ao PRP sua reinserção ao trabalho.

Assim, a saúde do trabalhador, incluindo a reabilitação profissional, ainda é um direito constitucional a ser conquistado na prática. A inclusão das questões trabalhistas e sanitárias dos trabalhadores nas questões de sustentabilidade das políticas econômicas é de importância central para que se supere a situação de sua sobreposição ao bem-estar da população, cujo ônus recai sobre o próprio Estado, seja no SUS, seja na Previdência Social ou mesmo na Assistência Social [...] (MAENO; VILELA, 2010, p.93)

O programa de reabilitação profissional precisa com urgência ser repensado, para atender a demanda do segurado de maneira eficiente e efetiva. É preciso acompanhar as mudanças no mundo do trabalho e seus desafios, realizando um aproximação do PRP com as empresas a fim de atender às exigências e mudanças na esfera produtiva. Isso significaria um avanço na qualidade dos serviços. Almejamos que essa investigação possa contribuir para despertar a 
dormência social para as violências e injustiças que ocorre com os segurados da previdência social, parcela das populações excluídas provocadas pelas chamadas instituições de proteção social que observamos e ignoramos no dia-a-dia.

\section{CONSIDERAÇÕES FINAIS}

O direito a seguridade social é garantido pela CF /88 a todo cidadão. E ele tem como objetivo possibilitar a efetivação do bem estar social, garantindo os mínimos necessários à sobrevivência. Isto ocorre quando o cidadão fica limitado na promoção do seu sustento ou de sua família por razões de doença, desemprego, maternidade, invalidez, reclusão ou outras razões, ele recorre à seguridade social.

A proteção da seguridade social é composta por três políticas: política de Saúde (SUS): direito de todos e dever do Estado, independente de contribuição ou filiação para seu custeio; política de Assistência Social que independente de contribuição será prestada a quem dela necessitar em situações de enfrentamento a pobreza e provimento de condições/recursos; e a política de Previdência Social sendo um sistema de proteção social destinado a pessoa que contribui, com características de um seguro social, através de benefícios substituindo a renda do trabalhador quando esse perde a capacidade de trabalho.

Dentre os benefícios prestados pela previdência social, há o Programa de Reabilitação Profissional (PRP) destinado aos segurados que após acidente de trabalho ou doença ocupacional, apresentam limitações no exercício de suas atividades laborais, e não tem condições de retomar as atividades anteriores, sendo necessário reabilitá-lo em outra função.

O segurado após acidente de trabalho ou doença ocupacional (quando gera afastamento do trabalho), passa ser assistido pela Previdência social. Assim, inicia-se sua peregrinação no INSS. Nesse momento o segurado encontra-se fragilizado, em tratamento médico e é submetido a uma série de perícias médicas para comprovar a necessidade de estar afastado do trabalho. Sabemos que o afastamento do trabalho onera custos tanto para a previdência social quanto para a empresa. Pois, estando na ativa o segurado estaria contribuindo para o INSS, e não o INSS tendo que disponibilizar o benefício. E para a empresa será necessário substituir o trabalhador temporariamente ou até contratar outro para exercer as atividades, conseqüentemente onerando custos.

A política de previdência social é contributiva, ou seja, para ter direito é preciso contribuir, cumprir os prazos de carência para assim ter qualidade de segurado e usufruir do rol de benefícios. Porém, quando se trata do PRP, surgem várias indagações/questionamento sobre sua efetiva e eficiente atuação.

$\mathrm{Na}$ década de 90, visualizamos as transformações no cenário econômico, acarretando o enxugamento na máquina pública. E não foi diferente no âmbito da previdência social e mais especificamente no Centros de Reabilitação Profissional (CRP) e os Núcleos de Reabilitação Profissional (NRP), ocorrendo o sucateamento da capacidade instalada e dos recursos humanos. As mudanças continuaram, e 
em 2001 foi i implantado o Projeto Reabilita que vigora nos dias atuais. $\mathrm{O}$ projeto tem por finalidade nomear orientadores profissionais, e não mais as equipes de profissionais para realizar o processo de recolocação institucional do segurado da Reabilitação Profissional. O fato é que muitos desses orientadores profissionais não têm familiaridade com o mundo real do trabalho, seus desafios, exigências e suas complexidades. Assim, a atuação do orientador profissional restringe-se apenas a condução do processo precário de reinserção do segurado com a mínima interferência do Estado, ficando a cargo da empresa de vínculo.

Já as empresas, a fim de evitar multas e de cumprir a exigência legal, reinserem o acidentado, mas não proporcionam a esse trabalhador recolocação em funções mais adequadas aos atuais limites que atendam também ao desejo do trabalhador consideração suas habilidades e aptidões. Nesse contexto o segurado é penalizado, conseqüência de uma política pública reducionista e de uma gestão que delimita o número de segurados em PRP; não levando em consideração a eficiência e a eficácia do programa e as reais necessidades dos trabalhadores.

$\mathrm{Na}$ perspectiva dos participantes dessa pesquisa como na revisão bibliográfica, revela que o processo de reabilitação profissional e a sua reinserção ao trabalho causa um misto de sentimentos, de expectativas, de receios e medos ao trabalhador. E que a reabilitação profissional não é garantia de estabilidade no emprego, pois muitas vezes após a estabilidade o trabalhador é dispensado da empresa, e por sua vez fica à mercê do mundo do trabalho, tendo que disputar uma vaga de emprego de maneira desleal em decorrência de suas restrições físicas e psíquicas. Embora os trabalhadores que participaram do PRP enquadram-se nas cotas para portadores com deficiência (PCD), conforme expresso na legislação, nem isso é capaz de manter os trabalhadores reabilitados nas empresas.

Assim, ao finalizar esse estudo concluímos que a reabilitação profissional de trabalhadores com restrições, ainda tem um longo caminho a percorrer na construção de um estado de bem estar social. É imprescindível a promoção do diálogo entre as áreas intersetoriais desse contexto, exigindo diretrizes por parte do Estado, desenvolvendo projetos locais e regionais. Sem dúvida é preciso que a Previdência Social resgate seu conceito de excelência, seu caráter público e seu papel na seguridade social.

\section{REFERÊNCIAS}

BARELA, Wagner; MUSSI, Cristiane Miziara. Direito Previdenciário- Série concursos públicos. 7. Ed. São Paulo: Editora Método, 2010 p.31.

BARROS, V.A.; SALES, M.M.; NOGUEIRA, M.L.M. Exclusão, favela e vergonha: uma interrogação ao trabalho. In: GOULART, I.B., org. Psicologia organizacional e do trabalho: teoria, pesquisa e temas correlatos. 1 ed. São Paulo: Casa do Psicólogo, 2002. p. 323-335.

BRANT, L.C.; MINAYO-GOMEZ, C. A transformação do sofrimento em adoecimento: do nascimento da clínica à psicodinâmica do trabalho. Ciência e Saúde Coletiva, Rio de Janeiro, v.9, n.1, p. 213-223, 2004.

BRASIL. Segurança Ações regressivas colocam freio à impunidade no trânsito. Previdência Social, AnoIV, nº 08- Jan. Abril, 2014. Constituição da República Federativa do 
Brasil, 35 Edição. São Paulo: Saraiva, 2005.

Decreto $\mathrm{n}^{\circ} 269$, de 18 de setembro de 2008. Aprova o texto da convenção 102 da Organização Internacional do Trabalho - OIT, relativa a fixação de normas mínimas de seguridade social, adotada em genebra, em 28 de junho de 1952. Disponível em:

<http://www.lexml.gov.br/urn/urn:lex:br:federal :decreto.legislativo:2008-09-18;269>. Acesso em: 11 jun de 2015 .

Decreto $n^{\circ}$. 6.934, de 11 de agosto de 2009. Aprova a Estrutura Regimental e o Quadro Demonstrativo dos Cargos em Comissão, das Funções Gratificadas e das Funções Comissionadas do Instituto Nacional do Seguro Social - INSS, dispõe sobre remanejamento de cargos em comissão e funções gratificadas, e altera o Anexo II ao Decreto $\mathrm{n}^{\circ} 6.417$, de 31 de março de 2008, que aprova a Estrutura Regimental e Quadro Demonstrativo dos Cargos em Comissão e das Funções Gratificadas do Ministério da Previdência Social, e dá outras providências. Disponível em: <http://www2.camara.leg.br/legin/fed/decret/20 09/decreto-6934-11-agosto-2009-590429publicacaooriginal-115562-pe.html>. Acesso em: 15 de ago de 2015.

Decreto $\mathrm{n}^{\circ} 7.556$, de 24 de agosto de 2011. Aprova a Estrutura Regimental e o Quadro Demonstrativo dos Cargos em Comissão, das Funções Gratificadas e das Funções Comissionadas do Instituto Nacional do Seguro Social - INSS e remaneja cargos em comissão, funções comissionadas e gratificadas. Disponível em:

<http://www.planalto.gov.br/ccivil_03/_Ato201 1-2014/2011/Decreto/D7556.htm\#art6> .Acesso em 15 de ag de 2015.

Lei 10.836, de 09 de janeiro de 2004.

Criação do bolsa família e dá outras

providencias. Disponível em:

<http://www.planalto.gov.br/ccivil_03/_ato2004 -2006/2004/lei/110.836.htm>. Acesso em:29 de jun de 2015.

Lei 8.080, de 19 de setembro de 1990.

Dispõe sobre as condições para a promoção, proteção e recuperação da saúde, a organização e o funcionamento dos serviços correspondentes e dá outras providências. Disponível em: <http://www.planalto.gov.br/ccivil_03/Leis/L80 80.htm>. Acesso em: 21 de jun de 2015.

Lei 8.213, de 24 julho de 1991. Dispõe sobre os Planos de Benefícios da Previdência Social e dá outras providências. Disponível em: <http://www.guiatrabalhista.com.br/legislacao/lei 8213.htm>. Acesso em: 07 ago de 2015.

Lei 8.472, de 07 de dezembro de 1993. Dispõe sobre a organização da Assistência Social e dá outras providências. Disponível em: <http://www.planalto.gov.br/ccivil_03/LEIS/L87 42.htm>. Acesso em: 21 de jun de 2015

CRUZ, A K G da. Auxílio-doença e sua relação com o direito do trabalho. Disponível em: <http://ambitojuridico.com.br/site/?n_link=revist a_artigos_leitura\&artigo_id=10903\&revista_cade rno $=25$ > . Acesso em: 26 mai 2014.

FERREIRA, Ângelo Márcio. O Trabalho, a Habilitação e a reabilitação Profissional no âmbito da Previdência Social, 2009. Disponível em:

<http://www.ieprev.com.br/conteudo/id/12899/t/ parceiros.aspx> . Acesso em: 01 de set de 2015.

GUIZZO, D S. Axioma Jurídico. Direito Previdenciário, 2005.

IBRAHIM, Fábio Zambitte. Curso de Direito Previdenciário. 17 ed. - Rio de Janeiro: Impetus, 2012.

\section{INSTITUTO NACIONAL DO SEGURO} SOCIAL. Manual Técnico de Procedimentos da Área de Reabilitação Profissional. Diretoria de Saúde do Trabalhador - DIRSAT, 2011.

MAENO, M.; VILELA, R. A. G. Reabilitação profissional no Brasil: elementos para a construção de uma política pública. Revista Brasileira de Saúde Ocupacional, vol.35, no 121 jan/jun., 2010. Disponível em: <http://www.fundacentro.gov.br/rbso/BancoAne xos/RBSO \%20121\%20Reabilita\%C3\%A7\%C3\% A3o\%20profissional\%20no\%20Brasil.pdf $>$. Acesso em 14 de jul de 2015.

MARTINS, J.N.; ASSUNÇÃO, A.A. A dor na doença músculo-esquelética associada ao trabalho. Cadernos de Psicologia. Belo Horizonte, v.12, n.1, p. 61-76, 2002.

MARTINS, S P. Fundamentos de direito da 
seguridade social. $6^{\circ}$ edição. São Paulo: Atlas, 2005 .

MATSUO, M. M. Acidentado do trabalho. Reabilitação ou exclusão? 1997. 238 f. Dissertação (Mestrado em Sociologia) Faculdade de Filosofia, Letras e Ciências Humanas, Universidade de São Paulo, São Paulo, 1997.

\section{MATSUO, M. Acidentado do trabalho:} reabilitação ou exclusão? São Paulo:

Fundacentro, 2002. p. 238.

PINTO, G. A. A organização do trabalho no século XX: taylorismo, fordismo e toyotismo. São Paulo: Expressão Popular, 2007.

ROSIN-PINOLA, A. R.; SILVA, C. P. da; GARBULHO, N. de F. Implicações psicossociais para o acidentado de trabalho reinserido no mercado de trabalho e desempregado. Revista Brasileira de Orientação Profissional, São Paulo, v. 5, n. 2, p. 53-62, dez. 2004.

SAMPAIO, R.F.; NAVARRO, A.i G.;

MARTÍN, M.M. Incapacidades laborales: problemas em lá reinserción al trabajo.

Cadernos de Saúde Pública, Rio de Janeiro, v. 15, n. 4, p. 809-815, out-dez 1999.

SANTOS, M F dos. Direito Previdenciário. $7^{\circ}$ edição. São Paulo: Saraiva, p. 13, 2011.

SANTOS, M. A. A reestruturação produtiva e seus impactos na saúde do trabalhador. Serviço Social \& Sociedade, n. 82, Ano xxvi, jul 2005.

SARDÁ, J J; KUPEK, E; CRUZ, R. Preditores Biopsicossociais de Incapacidade Física e Depressão em Trabalhadores do Setor de Frigoríficos Atendidos em um Programa de Reabilitação Profissional. Acta Fisiátrica, São Paulo, v. 16, n. 2, p. 76 - 80, jun.2009.

TAKAHASHI, M. A. B. C; IGUTI, A. M. As mudanças nas práticas de reabilitação profissional da Previdência Social no Brasil: modernização ou enfraquecimento da proteção social? Rio de Janeiro, Cad. Saúde Pública, nov. 2008. Disponível em:

<http://www.scielo.br/pdf/csp/v24n11/21.pdf>. Acesso em 20 de set de 2014.
TAVARES, M L. Direito Previdenciário. $2^{\circ}$ edição. 2000.

\section{Como citar este artigo (Formato ABNT):}

LIMA, Tatiane Rodrigues Araújo. Processo de reabilitação profissional, sob a perspectiva do segurado da previdência social. Educação, Psicologia e Interfaces, vol.1, n.2, p. 78-92, 2017. DOI: $\quad$ https://doi.org/10.37444/issn-2594$\underline{\text { 5343.v1i2.35 }}$

Recebido: 10/09/2017.

Aceito: 19/11/2017. 